\title{
Sensory and Chemical Flavor Analyses of Tomato Genotypes Grown in Florida during Three Different Growing Seasons in Multiple Years
}

\author{
Elizabeth A. Baldwin ${ }^{1}$ \\ Horticultural Research Laboratory, United States Department of Agriculture-Agriculture Research \\ Service, 2001 South Rock Road, Fort Pierce, FL 34945 \\ John W. Scott \\ Gulf Coast Research and Education Center, University of Florida, 14625 CR 672, Wimauma, FL 33598
}

Jinhe Bai

Horticultural Research Laboratory, United States Department of Agriculture-Agriculture Research Service, 2001 South Rock Road, Fort Pierce, FL 34945

\begin{abstract}
AdDitional INDEX wORDs. Solanum lycopersicum, breeding, sugars, acids, aroma, volatiles, sweet, sour
ABstract. Thirty-eight tomato (Solanum lycopersicum L.) genotypes were analyzed for sensory attributes "sweet," "sour," and "overall flavor" over 7 years, one to three seasons per year (March, June, and December) as well as for physical and chemical flavor-related attributes including color, sugars, acids, and aroma volatiles (6-7 years). Principal component analysis of the data of nine genotypes showed that for harvest season, December-harvested fruit were generally associated with more acids and sourness perception and less sugars and sweetness perception and, therefore, lower overall flavor ratings compared with June-harvested fruit. March-harvested samples were intermediate. Despite the seasonal variations, there were significant differences between genotypes for sensory perception of sweetness, sourness, and flavor, between seasons for sourness and flavor, and between years for flavor, with some interactions between genotypes, seasons, and years. In addition to sugar and acid measurements, 29 aroma volatiles were evaluated in 33 genotypes over the seasons. Eleven volatiles were found to positively correlate with flavor perception and 13 enhanced flavor along with the soluble solids/titratable acidity ratio in a two-predictor model, providing aroma targets for breeders. Among the genotypes evaluated most frequently were the Florida industry standard 'Florida 47' and University of Florida hybrid 'Fla. 8153' which was released in 2006 and is now marketed as Tasti-Lee ${ }^{\circledR}$. 'Florida 47' was almost always rated lower for sweet and overall flavor compared with 'Fla. 8153'. On a 1-9 hedonic scale, where 1 was least sweet, sour, or flavorful and 9 was most sweet, sour, or flavorful, average scores over the 7 years were 3.8 and 5.1 for sweet and 4.1 and 5.7 for overall flavor for 'Florida 47' and 'Fla. 8153', respectively. Other genotypes related to 'Fla. 8153', including its parents, were also rated high for sweet and overall flavor compared with 'Florida 47' and other commercial cultivars grown in Florida. Correspondingly, sugar measurements were higher, while acid measurements were slightly lower for 'Fla. 8153' compared with 'Florida 47'. Thirteen out of 29 aroma compounds showed differences between these two genotypes, with eight being higher in 'Fla. 8153' (including many fruity/floral notes) and four higher in Florida 47 (C-5 and $\mathrm{C}-6$ aldehydes and alcohols giving green notes). This provides a useful chemical model for two genotypes that differ in flavor quality that can be exploited by breeders seeking to improve flavor.
\end{abstract}

Dissatisfaction with the flavor of commercial tomato cultivars has been documented in the past (Bruhn et al., 1991; Klee, 2010; Klee and Tieman, 2013; Tieman et al., 2012) and is still a subject of much attention. Some believe that domestication events in Central America and Europe created genetic bottlenecks resulting in low diversity in the cultivated tomato, including flavor components (Jiménez-Gómez and Maloof, 2009; Klee, 2010; Tieman et al., 2012). However, flavor variation necessary to develop superior-tasting tomato cultivars may be available in a large tomato breeding program. This is

Received for publication 27 May 2015. Accepted for publication 30 July 2015. This work was partially funded by the Florida Tomato Committee.

This article is a U.S. Government work and is in the public domain in the United States. Mention of a trademark or proprietary product is for identification only and does not imply a guarantee or warranty of the product by the U.S. Department of Agriculture. The U.S. Department of Agriculture prohibits discrimination in all its programs and activities on the basis of race, color, national origin, gender, religion, age, disability, political beliefs, sexual orientation, and marital or family status.

${ }^{1}$ Corresponding author. E-mail: Liz.Baldwin@ars.usda.gov. a matter of combining the proper components, which is not an easy task. Regardless, fresh-market tomatoes sold in supermarkets still garner much criticism concerning their lack of flavor or off-flavor. This is primarily due to other breeding priorities such as marketable yield and shipping ability, environmental conditions during plant cultivation that have a profound effect on flavor, harvest practices that do not allow the fruit to initiate ripening on the mother plant (Baldwin et al., 2011; Klee and Tieman, 2013; Maul et al., 1998), and postharvest practices that include chilling the fruit to prolong storage shelf life (Bai et al., 2011; Baldwin et al., 2011; Maul et al., 2000). In addition, breeders have difficulty in selecting such a complex trait since flavor volatiles, sugars, and acids involve multiple chemical pathways in the plant and complex perception mechanisms in humans (Bartoshuk and Klee 2013; Klee and Tieman, 2013). Of these drawbacks, the most important is genetics because it holds the flavor potential for a cultivar. However, the full flavor potential inherent in the genetics of a tomato may not be realized because of less than optimal environmental conditions, 
harvest maturity, and postharvest handling practices (Baldwin et al., 2007). Conversely, if the genetic potential for good flavor is not there, then no amount of careful cultivation, harvesting, and handling can make up for this deficiency. Despite many advances in the understanding of the components of tomato flavor, profound, yet not well understood, environmental effects on flavor contribute to selection difficulties in developing breeding lines with superior flavor; in fact, $\mathrm{F}_{2} / \mathrm{F}_{3}$ generation narrow sense heritability was only 0.1 (Scott, 2002). Environmental conditions significantly affected organoleptic quality for true breeding cultivars (Carli et al., 2011). The direct effect of solar radiation on sugars, a major component of tomato flavor, has been well documented (Davies and Hobson, 1981; Georgelis et al., 2006) while high $\mathrm{N}: \mathrm{K}$ fertilizer ratios have negative correlations with sugars (Mikkelsen, 2005). Such effects have clouded our understanding of the suite of aromatic volatiles that are important to good tomato flavor. For this reason, the University of Florida tomato breeding program emphasized flavor analysis in its screening program for advanced genotypes over 7 years, with two to three seasons per year, to compare promising genotypes with standard commercial cultivars using sensory consumer panels combined with chemical analyses of flavor compounds. Previous studies spiking deodorized tomato homogenate with volatile standards, with or without added sugars and acids, determined the important contribution of various volatiles, known to be present in tomatoes, to overall flavor (Baldwin et al., 2007, 2008). Armed with this information and information from other studies on tomato aroma and aroma thresholds (Buttery, 1993; Buttery et al., 1987, 1989; Tandon et al., 2003; Tieman et al., 2012), the objectives of this study were 3-fold: first, to evaluate soluble solids (SS), titratable acidity (TA), SS/TA ratio, individual sugars, individual acids, and 29 aroma volatiles over multiple seasons and years to better determine their importance under diverse environmental conditions; second, to determine chemical differences between two genotypes perceived to have large differences in overall flavor to determine desirable flavor chemicals and their levels; and finally to gain insights into tomato flavor in general, and how we perceive it. The data from this study, especially on the complex aroma volatile component, should add to our understanding of tomato flavor and provide a possible model for breeders in selection of flavor quality.

\section{Materials and Methods}

Field EXPERIMENTS. Tomato genotypes for flavor analysis were grown from 2003 to 2010 in 12 field trials in Florida that encompassed spring (June) and fall (December) harvest seasons mostly at the Gulf Coast Research \& Education Center (GCREC) on the central west coast (Wimauma) and winter harvest seasons (March) at the Tropical Research \& Education Center (TREC) in south Florida (Homestead). Fruit of two genotypes, 'Ugly Ripe' and Cluster [also called tomato on the vine (TOV)] were bought at the table-ripe stage at a supermarket. Four December-harvest trials were done in 2003-05, and 2008; six June-harvest trials were done in 2004, 2005, and 2007-10; and three March-harvest trials were done in 2005, 2007, and 2008 (Table 1). The 2003 and 2004 trials were conducted at Bradenton except in Fall 2004 when the tomatoes were grown on a grower farm within $20 \mathrm{~km}$ of GCREC. The GCREC Bradenton soil type was classified as Eau Gallie fine sand with $1 \%$ organic matter and a $\mathrm{pH}$ of 6.5 , thereafter the GCREC trials were conducted at Balm where the soil is classified as a Myakka fine sand siliceous hyperthermic Oxyaquic Alorthod with $1.5 \%$ organic matter and a $\mathrm{pH}$ of 7.3 . The soil type at TREC was a Krome very gravelly loam with a high $\mathrm{pH}$ (7.8). The plants in the field were grown under standard Florida practices on fumigated soil under plastic-covered beds, and they were staked and tied (Olson et al., 2010). GCREC and the grower field plots were arranged in randomized complete block designs with two blocks and five to eight plants per plot. TREC trials were random single plots of 10 plants. Fruit at the table-ripe stage [U.S. Department of Agriculture stage 6, red, and for these samples, with $100 \%$ of surface having red color, and calculated on days past pollination for a genotype based on breeder experience (USDA, 2015)] were harvested the day before or on the morning of sensory panel analysis for all trials. All harvested fruit were stored at $24{ }^{\circ} \mathrm{C}$ in a laboratory until sensory panels were conducted. In the replicated trials, fruit were harvested and bulked from plants of both blocks for each genotype. Seed for December-harvest trials were sown in greenhouses from 20 July to 4 Aug., field transplanting was from 28 July to 13 Aug., and sensory panels were conducted from 5 to 19 Dec. Seed for June-harvest trials were sown in greenhouses from 28 Jan. to 16 Feb., field transplanting was from 11 to 25 Mar., and sensory panels were conducted from 7 to 14 June. Seed for March-harvest trials were sown in greenhouses from 5 to 10 Oct., field transplanting was from 10 to 14 Nov., and sensory panels were conducted from 8 to 11 Mar. Temperature, rainfall, and solar radiation data for spring and fall seasons at GCREC were presented by Georgelis et al. (2006). Within genotype, table-ripe, defect-free fruit with uniform size and color were used for both sensory and chemical analysis generally within $1 \mathrm{~d}$ of harvest as mentioned (held at ambient temperature until tasted and homogenized for chemical analyses). Sensory, SS, TA, individual sugars, and color analyses were conducted on all harvests in 2003-10. Individual acid (malate and citrate) analyses were done for 2007-10 trials and individual aroma volatiles from 2003-05 and 2007-10 (missing for 2006). A total of 38 genotypes including breeding lines, experimental hybrids, and commercial hybrid cultivars were tested in 13 sensory trials (Tables 1 and 3). Each harvest contained five to eight cultivars/genotypes. 'Fla. 8153' (TastiLee $^{\circledR}$ ) was tested in 12 out of the 13 sensory trials, and 'Florida 47' was tested in 11 out of 13 sensory trials. These two genotypes were then specifically compared because 'Fla. 8153' had scored higher for overall flavor than 'Florida 47' in six of seven panels (Scott et al., 2008). Other genotype/cultivars were tested in one to four sensory trials.

SENSORY ANALYSIS. The tomato fruit were washed, stem scar removed, and cut into wedges (about eight wedges/fruit) from at least 12 fruit per genotype, mixed, and presented on paper plates to a consumer panel consisting of 23 to 58 panelists (aged $18-65$ years, roughly $40 \%$ to $60 \%$ female, the balance being male) per session (Stone and Sidel, 1997) with a randomized alphabetical code $(\mathrm{A}-\mathrm{H})$ presented to the panelists, so that they tasted samples in a randomized order. Plates from five to eight genotypes were placed on a table, with mixed slices from four fruit, and panelists were handed a score sheet with the sample order randomized (some score sheets started with sample A, others on sample B or C, etc.), with which to rate the intensity of sweetness, sourness, and overall flavor on a 1 to 9 hedonic scale, where 1 was least sweet, sour, or flavorful and 9 was most 
Table 1. Brief description of each tomato genotype used in this study of sensory and chemical flavor and the year and season (month) tested.

\begin{tabular}{|c|c|c|}
\hline Genotype & Descriptors $^{\mathrm{z}}$ & Years and seasons tested ${ }^{y}$ \\
\hline 8630 & $\begin{array}{l}\text { Backcross of } 8044 \text { with } 8153 \text { parent 7907, high sugar, possibly fruity/floral, } \\
\text { crimson }^{x}\end{array}$ & $2008 \mathrm{M}, 2008 \mathrm{~J}$ \\
\hline 'Fla. 8153' & 'Tasti-Lee'. Hybrid selected for good flavor, cross of 7907 and 8059, crimson & $\begin{array}{l}2003 \mathrm{D}, 2004 \mathrm{~J}, 2004 \mathrm{D}, 2005 \mathrm{M}, 2005 \mathrm{~J} \\
\text { 2005D, 2007M, 2007J, 2008M, } \\
2008 \mathrm{~J}, 2008 \mathrm{D}, 2009 \mathrm{~J}, 2010 \mathrm{~J}\end{array}$ \\
\hline 7907 & Parent of 8153 ('Tasti-Lee') low acid, sweet taste, crimson & 2008M, 2008D, 2009J \\
\hline 5836 & Harris Moran hybrid, sweet low acid & $2005 \mathrm{D}$ \\
\hline $7907 \times 8630$ & Hybrid of 7907 and 8630 , sweet, very good flavor in taste panel, crimson & $2008 \mathrm{D}, 2009 \mathrm{~J}$ \\
\hline $8059 \times 8629$ & Hybrid of 8059 and 8629 & $2008 \mathrm{D}, 2009 \mathrm{~J}$ \\
\hline 8629 & Backcross of 8570 with 8153 parent 7907 , high sugar, very good flavor, crimson & 2008D, 2009J, 2010J \\
\hline 8792 & $\begin{array}{l}\text { Backcross of } 8629 \text { with } 8059 \text {, high sugar, possibly fruity/floral, very good flavor, } \\
\text { crimson }\end{array}$ & $2010 \mathrm{~J}$ \\
\hline 8408 & Hybrid with good flavor, not crimson & $2004 \mathrm{D}, 2005 \mathrm{~J}$ \\
\hline 2366 & West Virginia State University breeding line, good flavor, not crimson & $2008 \mathrm{~J}$ \\
\hline $7907 \times 8629$ & $\begin{array}{l}\text { Hybrid of } 7909 \text { and } 8629 \text { parents, high sugar, very good flavor in taste panel, } \\
\text { crimson }\end{array}$ & $2008 \mathrm{D}, 2009 \mathrm{~J}$ \\
\hline 8570 & Inbred with intense flavor, sometimes fruity/floral, crimson & 2005D \\
\hline 8280 & Inbred with sweet-vegetative flavor, crimson & 2003D \\
\hline 9250 & Similar pedigree to 8629 , crimson & 2008M, 2008J \\
\hline 8309 & Inbred with fruity-vegetative flavor, not crimson & 2004J \\
\hline 802 & $\begin{array}{l}\text { Jointless pedicel hybrid with University of Florida and J.W. Strobel parents, good } \\
\text { flavor, crimson }\end{array}$ & $2007 \mathrm{M}$ \\
\hline 8298 & F3 line with good flavor, crimson & 2004J \\
\hline 925 & $\begin{array}{l}\text { Jointless pedicel hybrid with University of Florida and J.W. Strobel parents, good } \\
\text { flavor, crimson }\end{array}$ & $2007 \mathrm{M}$ \\
\hline 'Florida 91' & Commercial hybrid, flavor on sour side, not crimson & 2004D \\
\hline 'Solar Set' & Hybrid that did well in earlier taste panels, not crimson & $2003 \mathrm{D}$ \\
\hline ‘Solar Fire’ & Commercial hybrid, flavor on sour side, not crimson & 2004J, 2004D, 2005M \\
\hline 6153 & Commercial hybrid with good flavor grown in southern Florida, not crimson & $2007 \mathrm{M}$ \\
\hline 'Florida 47' & $\begin{array}{l}\text { Commercial hybrid widely grown in Florida and southeastern U.S., flavor on sour } \\
\text { side, not crimson }\end{array}$ & $\begin{array}{l}2003 \mathrm{D}, 2004 \mathrm{~J}, 2004 \mathrm{D}, 2005 \mathrm{M}, 2005 \mathrm{~J} \\
\text { 2005D, 2007M, 2007J, 2008M, } \\
\text { 2008J, 2008D, 2009J }\end{array}$ \\
\hline 8413 & Hybrid of $8059 \times 8293$ parents, good flavor, not crimson & 2007J \\
\hline 8735 & Large fruited inbred, nice locules, good flavor, crimson & $2010 \mathrm{~J}$ \\
\hline 8787 & $\begin{array}{l}\text { Jointless pedicel hybrid with University of Florida and J.W. Strobel parents, good } \\
\text { flavor crimson }\end{array}$ & $2010 \mathrm{~J}$ \\
\hline 'Ugly Ripe'w & Commercial hybrid with heirloom appeal, store bought fruit tested, not crimson & 2004D, 2005M, 2005J \\
\hline Cluster $^{\mathrm{w}}$ & $\begin{array}{l}\text { Tomato on the vine (TOV) store bought samples tested, cultivar(s) unknown, not } \\
\text { crimson }\end{array}$ & 2004J, 2005J, 2005D \\
\hline
\end{tabular}

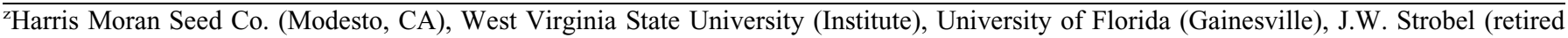
University of Florida professor).

${ }^{\mathrm{y}} \mathrm{M}=$ March, $\mathrm{J}=$ June, $\mathrm{D}=$ December.

${ }^{\mathrm{x}}$ Crimson $\left(\mathrm{og}^{\mathrm{c}}\right)$ gene (Thompson et al., 1965).

wStore-bought.

sweet, sour, or flavorful. Panelists were asked to taste more than one wedge and to partake of water and unsalted crackers between samples to cleanse their pallets. Plates of fresh samples from another three to four fruit were put out three to four times during each panel. For chemical analysis, subsamples of $\approx 8$ to 12 slices per genotype were taken from each of the three to four plates/genotype presented to the panel. Wedges were homogenized in a blender (Waring Products Corp., Torrington, CT) 
for $30 \mathrm{~s}$, allowed to stand for $3 \mathrm{~min}$ and $25 \mathrm{~mL}$ removed to a smaller blender with $10 \mathrm{~mL}$ room temperature-saturated $\mathrm{CaCl}_{2}$, blended for $10 \mathrm{~s}$, pipetted into $10-\mathrm{mL}$ gas chromatography (GC) vials and flash frozen in liquid nitrogen for volatile samples and transported back in Styrofoam container with liquid nitrogen (Baldwin et al., 2011). The rest of the homogenate was put in a separate container on ice for transport to the USDA laboratory, where they were stored at $-20{ }^{\circ} \mathrm{C}$ for sugar/ acid/color samples and the $\mathrm{GC}$ vials at $-80{ }^{\circ} \mathrm{C}$ for volatile samples until analysis. This resulted in three to four composite replications for sugar, acid, volatile, and color measurements per genotype from the same fruit presented to the panelists.

Sugar analyses. The SS analysis was determined using a refractometer (RX-5000; Atago USA, Bellevue, WA), which was later replaced with a different model (PR-101; Atago, Tokyo, Japan). For analysis of individual sugars and acids, $\approx 40 \mathrm{~g}$ of juice was extracted using $70 \mathrm{~mL}$ of $80 \%$ ethanol solution. The mixture was boiled for $15 \mathrm{~min}$, cooled and filtered with filter paper (Whatman No. 4; Whatman International, Maidstone, UK). The filtered solution was brought to $100 \mathrm{~mL}$ with $80 \%$ ethanol, and $10 \mathrm{~mL}$ was then filtered through a solid-phase extraction column (Sep-Pak C-18; Waters, Milford, MA) followed by a filter (0.45 $\mu \mathrm{m}$; Millipore, Watford, UK). Individual sugar analysis was performed by high-performance liquid chromatography (HPLC) with a pump (SpectraSYSTEM P4000; Thermo Separation Products, San Jose, CA) and a refractive index detector (1100 Series; Agilent, Santa Clara, CA) equipped with a $300 \times 6.5-\mathrm{mm}$ column (Sugar-Pak, Waters) (Baldwin et al., 1991, 1998, 2004) and quantified on a standard curve. The mobile phase was $10^{-4} \mathrm{M}$ ethylenediaminetetraacetic acid disodium calcium salt (CaEDTA) with a $0.5 \mathrm{~mL} \cdot \mathrm{min}^{-1}$ flow rate at $90{ }^{\circ} \mathrm{C}$. To better represent the sweetening power of the sugars, individual glucose and fructose concentrations were converted to sucrose equivalents [SE (Koehler and Kays, 1991)] by multiplying their concentrations by 0.74 and 1.73 , respectively (Baldwin et al., 1998; Maul et al., 2000). Levels of glucose and fructose were summed to comprise total sugars (TS). Sugars were quantified using a standard curve (Baldwin et al., 1991).

ACID ANALYSEs. Titratable acidity was determined by titrating to $\mathrm{pH} 8.1$ with $0.1 \mathrm{~N} \mathrm{NaOH}$ using an autotitrator (DL50; Mettler Toledo, Columbus, $\mathrm{OH}$ ) and expressed as citric acid equivalents. The $\mathrm{pH}$ was also determined during this process. Organic acids (citrate and malate) were analyzed using the same HPLC as above equipped with an organic acid column (OA-1000 Prevail; Alltech, Flemington, NJ) with a flow rate of $0.2 \mathrm{~mL} \cdot \mathrm{min}^{-1}$ at $35^{\circ} \mathrm{C}$ and a mobile phase of $0.01 \mathrm{~N} \mathrm{H}_{2} \mathrm{SO}_{4}$ and an ultraviolet detector (SpectraSYSTEM ultraviolet 6000 LP, Thermo Separation Products). The injection volume was $20 \mu \mathrm{L}$ using an autosampler (Series 200; Perkin Elmer, Norwalk, CT). Acids were quantified using a standard curve (Baldwin et al., 2010).

Aroma volatile analyses. Tomato volatile compounds were identified and quantified using head space analysis by gas chromatography [GC (model 8500, Perkin Elmer)] as in previous studies (Baldwin et al., 1991, 1998, 2004; Maul et al., 2000) using a headspace-sampler (HS-6, Perkin Elmer) equipped with a polar column $[0.53 \mathrm{~mm} \times 30 \mathrm{~m}, 1.0 \mu \mathrm{m}$ film thickness (Durowax; J\&W Scientific, Folsom, CA or Stabilwax; Resteck Corp., Bellefonte, PA)] and a flame ionization detector (FID), and in later years after purchasing an new GC system in 2006, using a different GC (model 6890, Agilent) (Bai et al., 2011) equipped with a polar (Stabilwax) and a nonpolar (low bleed) column $[0.53 \mathrm{~mm} \times 30 \mathrm{~m}, 1.5 \mu \mathrm{m}$ film thickness (HP-5,
Agilent)], where the flow was split equally between the two columns, and the detector was an FID. Since direct headspace volatile samples were not readily detectable by mass spectrometry (MS) (Song et al., 1997), confirmation by MS was accomplished by either a solvent extraction with ethyl ether as reported by Baldwin et al. (1991) for direct injection (for 2003-05 samples) or solid-phase micro extraction [SPME $(50 / 30 \mu \mathrm{m}$ DVB/CAR/PDMS; Supelco, Bellefonte, PA)] method (for 200710 samples) as reported by Wang et al. (2015). The instruments and settings were: for solvent direct injection: GC-MS (model 5890 GC + model 5970B MS; Hewlett-Packard, Norwalk, CT) with a $50-\mathrm{m}$ wide-bore $(0.31-0.32 \mathrm{~mm}$ film thickness) fused silica column of cross-linked 5\% phenylmethyl silicone. For the SPME injection: GC-MS (6890 GC + 5973N MS; Agilent) with a nonpolar column $[0.25 \mathrm{~mm} \times 60 \mathrm{~m}, 0.50 \mu \mathrm{m}$ film thickness (DB-5, Agilent)]. Volatile compounds were identified by the comparison of retention indices (RI) and mass spectra with library entries (NIST/EPA/NIH Mass Spectral Library version 2.0; National Institute of Standards and Technology, Gaithersburg, MD). The GC peaks for the aroma volatile compounds were quantified in microliters per liter using standard curves as determined by enrichment of bland tomato homogenate for both GC systems (Bai et al., 2011; Baldwin et al., 1991, 2004).

Fruit COLOR ANALYsis. Fresh homogenate was measured in a cuvette for color using a chromameter (CR-300; Minolta, Tokyo, Japan) calibrated to a white plate using the CIE L*, a*, b* system including chroma and hue (Baldwin et al., 1991).

Statistical analyses. SAS (version 9.3; SAS Institute, Cary, NC) was used for data analysis. Analysis of variance (ANOVA) was performed by using the general linear model (GLM) procedure for all individual measurements, including sensory panel, color values, sugar and acid contents, and volatiles where 23 to 58 individual panelists (replicates) were used in sensory panel attributes, and three to four replicates for all other chemical/physical measurements. For the analyses of each attribute, a randomized incomplete block split-split plot model was used with genotype (line) as the main plot factor, season as the subplot factor, and year as the sub-subplot factor. The main effects and the two-way interactions of each factor were included in the model. Multiple regression analysis (PROC REG) with two predictor variables was used to determine enhancement or suppression effects of individual volatile components to sweetness, sourness, or flavor. Cluster analysis (PROC CLUSTER) was used to test the distances between genotypes. All correlation analyses were conducted by using PROC CORR. For examination of the difference between the two most tested cultivars, FL 47 and Fla. 8153, the two independent-sample $t$ test (PROC TTEST) was used. Principal component analysis (PCA) was conducted by using XLSTAT (Addinsoft, New York, NY) with standardized data.

\section{Results and Discussion}

Some of the genotypes evaluated in this study were genetically related (such as parental lines of 'Fla. 8153') while others were tested because they had high sugars and/or interesting flavor notes [as determined by the breeder in the field (Table 1)]. These were compared with well-established cultivars that were grown or store bought (Table 1).

SENSORY ANALYSIS. There were differences for sweetness by genotype; sourness by genotype and season, and interactions 
Table 2. $F$ values and significant levels from ANOVA on sweetness, sourness and overall flavor of 38 tomato genotypes over 7 years, and one to three harvest seasons per year. ${ }^{\mathrm{z}}$

\begin{tabular}{lrrrrrrr}
\hline & & \multicolumn{5}{c}{$F$ value and significance } \\
\cline { 3 - 8 } & df & \multicolumn{2}{c}{ Sweetness } & \multicolumn{2}{c}{ Sourness } & \multicolumn{2}{c}{ Overall flavor } \\
\hline Genotype (G) & 37 & 5.45 & $* * * y$ & 4.1 & $* * *$ & 7.08 & $* * *$ \\
Season (S) & 2 & 1.61 & & 5.42 & $* *$ & 8.96 & $* * *$ \\
Year (Y) & 6 & 1.28 & 2.02 & & 1.07 & $* * *$ \\
$\mathrm{G} \times \mathrm{S}$ & 18 & 1.13 & 1.97 & $* *$ & 1.22 & \\
$\mathrm{G} \times \mathrm{Y}$ & 10 & 0.96 & 2.18 & $*$ & 1.42 & $*$ \\
$\mathrm{~S} \times \mathrm{Y}$ & 3 & 0.04 & 3.12 & $*$ & 0.74 & \\
\hline
\end{tabular}

z38 genotypes listed in Table 1; 2003-05 and 2007-10; March, June, and December.

$\mathrm{y} * * *$ and $* * *$ indicates significance at $P \leq 0.05,0.01$, and 0.001 , respectively.

for genotype by season, genotype by year, and season by year; and for overall flavor ratings by genotype, season, and year, and a genotype by year interaction (Table 2). Sweetness scores ranged from 3.1 to 5.6, sourness from 2.9 to 5.3, and flavor from 3.3 (store-bought cluster tomato) to 5.7 (genotypes Fla.: 8630, 8153,7907 , and 5836) (Table 3). Also rated low in flavor were store-bought 'Ugly Ripe' and field-grown Fla. 8787, Fla. 8735, Fla. 8413, and industry standard 'Florida 47'. 'Fla. 8153', later trademarked as Tasti Lee ${ }^{\circledR}$ (Scott et al., 2008), was rated in almost every panel over the 7 years as was industry standard 'Florida 47' (Table 1). Comparing these two cultivars, 'Fla. 8153 ' rated relatively high for sweetness (5.1), intermediate for sourness (4.3), and was in the highest group for flavor (5.7) compared with the industry standard, 'Florida 47 ' (3.8, 4.1, and 4.1 for sweetness, sourness, and flavor, respectively), averaged over 414 and 384 panelists, for 'Fla. 8153' and 'Florida 47', respectively.

Sugars AND ACIDS. There were differences for genotype, season, and year as well as genotype by season, genotype by year, and season by year interactions for SS, TS, glucose, fructose, SE, TA, SS/TA, citrate, malate (interaction for genotype by season only), and $\mathrm{pH}$ (Table 4). It is interesting that chemical sugar data were significant for season and year, while the sensory data were not (Table 2). This is likely due to the higher variation in the sensory than in the chemical data. Comparing just 'Florida 47' and 'Fla. 8153', 'Florida 47' had lower SS, TS, glucose, fructose, SE, SS/TA ratio, and $\mathrm{pH}$ while having higher TA, citrate, and malate (Table 5). This suggests that 'Fla. 8153' was generally sweeter than 'Florida 47', agreeing with the sensory ratings for sweetness, although the sensory panel did not rate 'Florida 47 ' higher than 'Fla. 8153 ' in sourness as the generally higher levels of acids for 'Florida 47' would indicate.

INTERNAL COLOR. There were differences for chromameter "L" (lightness), "a" (green to red color), "b" (blue to yellow color), chroma (brightness), and hue (lower values indicate red color) for genotypes, seasons, years, and all interactions between genotypes, seasons, and years (Table 4). Comparing 'Florida 47' and 'Fla. 8153', 'Florida 47' had higher L, lower a, and chroma and higher hue values (indicating less red color). There was no difference between these cultivars for $b$ values (Table 5). This is not surprising as 'Fla. 8153' is a high lycopene (red color pigment) cultivar (Scott et al., 2008) as a result of the crimson $\left(\mathrm{og}^{c}\right)$ gene (Thompson et al., 1965).

Aroma volatiles. For volatile research, only 29 genotypes listed in Fig. 1 were used. Twenty-nine volatiles were analyzed
Table 3. Sensory ratings for 38 tomato genotypes over 7 years with one to three harvest seasons per year. ${ }^{\mathrm{z}}$

\begin{tabular}{|c|c|c|c|c|c|c|c|}
\hline \multirow[b]{2}{*}{ Genotype } & \multirow[b]{2}{*}{ Panel number } & \multicolumn{2}{|c|}{ Sweetness $^{y}$} & \multicolumn{2}{|c|}{ Sourness } & \multicolumn{2}{|c|}{ Flavor } \\
\hline & & Mean & $\mathrm{SD}$ & Mean & $\overline{\mathrm{SD}}$ & Mean & $\overline{\mathrm{SD}}$ \\
\hline 8630 & 100 & 5.0 & 2.0 & 5.2 & 1.6 & 5.7 & $\overline{1.9}$ \\
\hline 'Fla. 8153' & 414 & 5.1 & 2.0 & 4.3 & 1.9 & 5.7 & 2.2 \\
\hline 7907 & 148 & 5.6 & 1.9 & 4.5 & 1.6 & 5.7 & 1.9 \\
\hline 5836 & 35 & 5.2 & 2.0 & 4.3 & 1.7 & 5.7 & 2.0 \\
\hline $8735 \times 8059$ & 30 & 5.1 & 1.7 & 4.8 & 1.6 & 5.6 & 2.2 \\
\hline $7907 \times 8630$ & 73 & 5.0 & 1.8 & 4.2 & 1.9 & 5.6 & 1.8 \\
\hline $8059 \times 8629$ & 73 & 4.7 & 1.8 & 4.9 & 2.1 & 5.5 & 1.8 \\
\hline 8629 & 103 & 4.9 & 1.9 & 4.7 & 1.8 & 5.5 & 2.1 \\
\hline 8792 & 30 & 5.0 & 1.9 & 4.4 & 1.5 & 5.5 & 2.4 \\
\hline 8408 & 52 & 4.7 & 2.0 & 4.2 & 1.8 & 5.4 & 2.1 \\
\hline 8485 & 45 & 4.2 & 2.0 & 4.6 & 1.8 & 5.4 & 2.1 \\
\hline 8393 & 29 & 4.5 & 2.0 & 5.3 & 1.9 & 5.4 & 2.2 \\
\hline Italx & 45 & 5.4 & 1.8 & 3.5 & 1.5 & 5.4 & 2.1 \\
\hline 8214 & 96 & 5.2 & 1.9 & 2.9 & 1.3 & 5.3 & 2.1 \\
\hline 2366 & 51 & 5.0 & 1.9 & 3.6 & 1.6 & 5.3 & 1.9 \\
\hline $7907 \times 8629$ & 73 & 4.5 & 1.8 & 4.3 & 1.9 & 5.2 & 2.0 \\
\hline 8570 & 35 & 4.3 & 2.0 & 4.5 & 1.9 & 5.1 & 2.1 \\
\hline 8280 & 26 & 5.0 & 1.7 & 4.3 & 2.2 & 5.1 & 1.7 \\
\hline 9250 & 100 & 4.5 & 1.8 & 4.1 & 1.7 & 5.0 & 2.0 \\
\hline 8309 & 23 & 4.5 & 2.0 & 4.6 & 2.0 & 5.0 & 2.1 \\
\hline 802 & 35 & 4.1 & 2.2 & 4.5 & 2.0 & 4.9 & 2.5 \\
\hline 8298 & 23 & 4.4 & 1.8 & 3.9 & 1.7 & 4.8 & 2.0 \\
\hline 925 & 35 & 4.1 & 2.0 & 3.9 & 1.9 & 4.8 & 2.2 \\
\hline 8059 & 99 & 4.6 & 1.9 & 4.1 & 1.9 & 4.8 & 2.1 \\
\hline 800 & 35 & 4.0 & 2.2 & 4.7 & 2.3 & 4.7 & 2.2 \\
\hline 803 & 35 & 4.1 & 1.9 & 4.5 & 2.0 & 4.7 & 2.2 \\
\hline 8610 & 45 & 4.1 & 1.8 & 4.5 & 1.8 & 4.6 & 2.0 \\
\hline 'Sanibel' & 95 & 4.1 & 2.1 & 3.8 & 1.9 & 4.4 & 2.3 \\
\hline 'Florida 91' & 23 & 4.5 & 2.0 & 4.4 & 1.7 & 4.3 & 2.1 \\
\hline 'Solar Set' & 26 & 4.2 & 2.2 & 3.9 & 1.9 & 4.3 & 1.9 \\
\hline 'Solar Fire' & 76 & 4.4 & 2.0 & 3.6 & 2.0 & 4.3 & 2.1 \\
\hline 6153 & 35 & 3.7 & 1.8 & 3.3 & 1.8 & 4.1 & 2.4 \\
\hline 'Florida 47' & 384 & 3.8 & 1.6 & 4.1 & 1.8 & 4.1 & 1.9 \\
\hline 8413 & 45 & 4.4 & 2.1 & 3.3 & 1.7 & 4.0 & 2.2 \\
\hline 8735 & 30 & 4.2 & 1.9 & 3.2 & 1.4 & 4.0 & 1.8 \\
\hline 8787 & 30 & 3.9 & 1.3 & 4.1 & 1.6 & 4.0 & 1.3 \\
\hline 'Ugly Ripe'x & 82 & 3.4 & 1.6 & 3.7 & 1.8 & 3.5 & 1.8 \\
\hline Cluster $^{x}$ & 58 & 3.1 & 1.6 & 3.6 & 2.0 & 3.3 & 2.0 \\
\hline
\end{tabular}

z2003-05 and 2007-10; March, June, and December.

y9-point scale with 1 = least sweet, sour, or flavorful and $9=$ most sweet, sour, or flavorful.

${ }^{\mathrm{x}}$ Store-bought.

over the years and seasons (Table 6) including acetaldehyde, hexanal, trans-2-pentenal, cis-3-hexanal, trans-2-hexenal, $2+$ 3-methylbutanal, trans-2-heptenal, phenylacetaldehyde, methional, benzaldehyde, citral, trans-2, trans-4-decadienal, acetone, 1-penten-3-one, 1-octen-3-one, 6-methyl-5-hepten2 -one, $\beta$-damascenone, geranylacetone, $\beta$-ionone, 2 -furanone, methanol, ethanol, $2+3$-methylbutanol, cis-3-hexenol, 2 -isobutylthiazole, linalool, 2-phenylethanol, methylsalicylate, and 1-nitro-2-phenylethane. There were differences between genotypes, seasons, years, and genotype by season interactions for 27 volatiles, except for citral (no difference for season) and $\beta$-ionone (only differences for genotype) (Table 6). There were also interactions for genotype by year and season by year for 18 volatiles (the 11 exceptions included hexanal, trans-2-pentenal, 
Table 4. F values and significant levels from ANOVA on sugar, acid, and color values of 38 tomato genotypes over 7 years, and one to three harvest seasons per year. ${ }^{\mathrm{z}}$

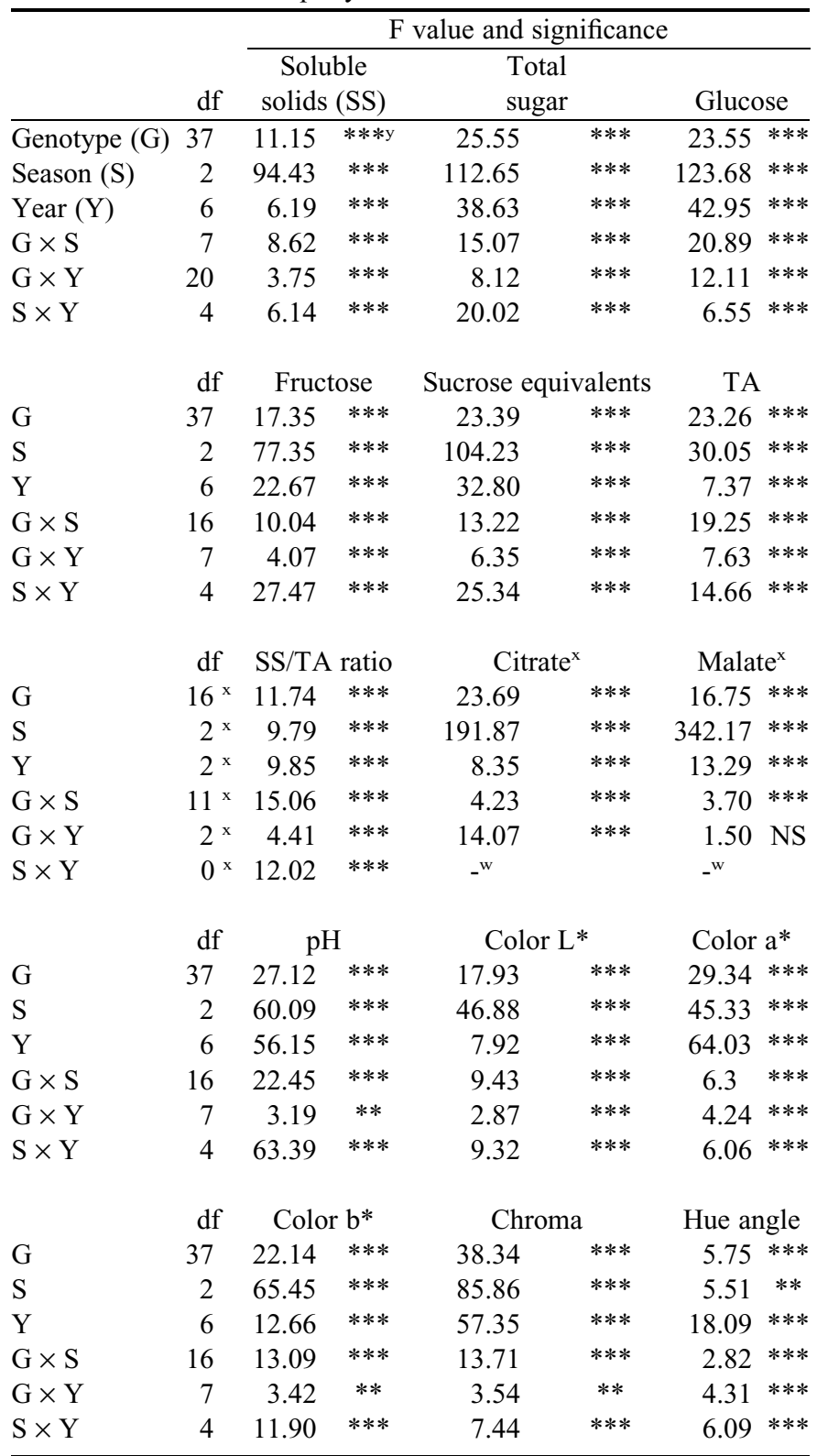

TA $=$ titratable acidity.

z38 genotypes listed in Table 1; 2003-05 and 2007-10; March, June, and December.

y*,** and $* * *$ indicates significance at $P \leq 0.05,0.01$, and 0.001 .

×2008-10 data only.

"No interaction was calculable.

cis-3-hexanal, $2+3$-methylbutanal, benzaldehyde, citral, $\beta$-ionone, 2-furanone, ethanol, cis-3-hexenol, and 1-nitro-2-phenylethane, for one or both interactions). Comparing 'Florida 47' and 'Fla. 8153' (Table 7), 'Fla. 8153' had higher levels of nine volatiles (acetaldehyde, 2 +3-methylbutanal, citral, methional, 6-methyl5 -hepten-2-one, geranylacetone, $\beta$-ionone, $2+3$-methylbutanol, and linalool), while 'Florida 47 ' had higher levels of four compounds, all C-6 aldehydes and one corresponding C-6 alcohol (cis-3-hexenal, trans-2-hexenal, trans-2-heptenal, and cis-3-hexenol). From this information, it would seem that
Table 5. Comparison of quality attributes between 'Fla. 8153' and 'Florida 47' tomatoes over 7 years, and one to three harvest seasons per year. $^{\mathrm{z}}$

\begin{tabular}{lccc}
\hline & Fla. 8153 & Florida 47 & $t$ test $^{\mathrm{y}}$ \\
\hline SS (\%) & 5.05 & 4.68 & $* * *$ \\
Total sugar (\%) & 2.32 & 1.93 & $* * *$ \\
Glucose (\%) & 1.11 & 0.96 & $*$ \\
Fructose (\%) & 1.20 & 0.99 & $* * *$ \\
Sucrose equivalents (\%) & 2.91 & 2.41 & $* * *$ \\
TA (\%) & 0.36 & 0.40 & $*$ \\
SS/TA ratio & 13.79 & 12.44 & $* * *$ \\
Citrate (\%) & 0.31 & 0.34 & $*$ \\
Malate (\%) & 0.04 & 0.07 & $* * *$ \\
pH & 4.32 & 4.27 & $* *$ \\
Color L* & 44.96 & 46.64 & $* *$ \\
Color a* & 32.28 & 30.11 & $* * *$ \\
Color b* & 27.98 & 28.38 & \\
Chroma & 44.16 & 43.60 & $* *$ \\
Hue angle $\left({ }^{\circ}\right)$ & 40.42 & 43.58 & $* * *$ \\
\hline
\end{tabular}

$\mathrm{SS}=$ soluble solids; $\mathrm{TA}=$ titratable acidity.

z2003-05 and 2007-10; March, June, and December.

y*, **, and *** indicates significance at $P \leq 0.05,0.01$, and 0.001 , respectively.

${ }^{\mathrm{x}}$ Measurements were done only in 2008-10 samples.

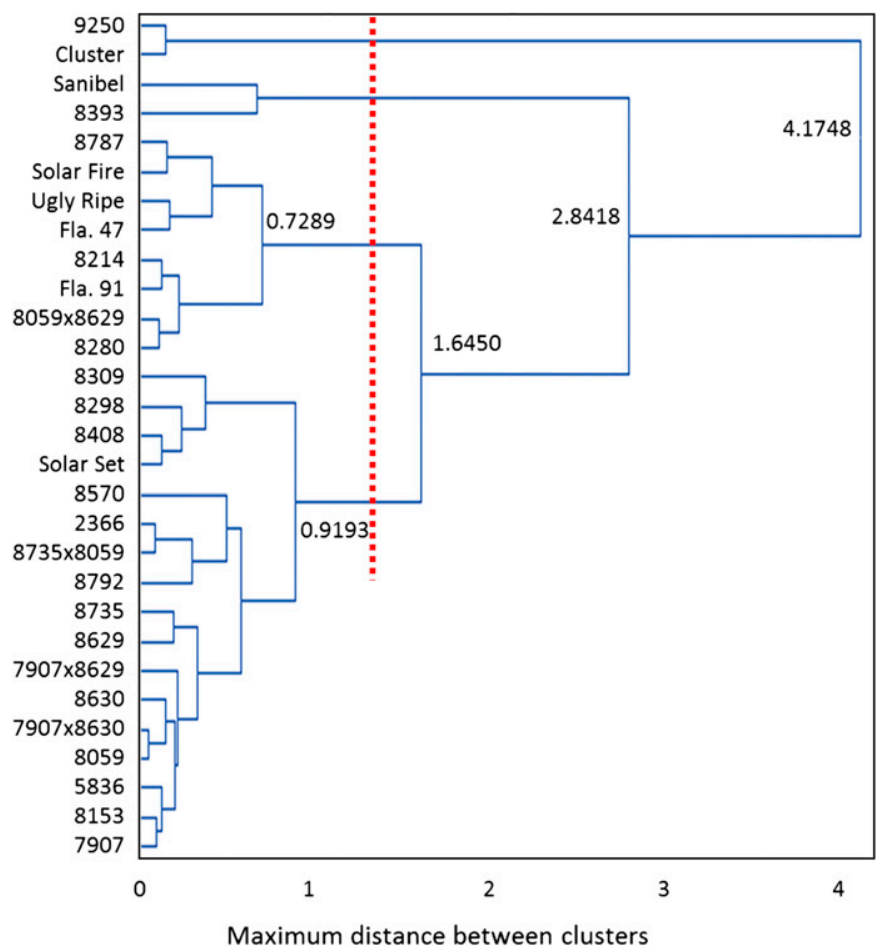

Fig. 1. Cluster analysis based on sensory and chemical data of 29 tomato genotypes over 6 years with one to three harvests per year. Vertical red-dashed line indicates significant cut-off for clusters.

'Florida 47' had higher levels of "green" notes (Table 7) denoted by the C-6 aldehydes and alcohols, and 'Fla. 8153' had higher levels of fruity floral notes from acetaldehyde, citral, 6-methyl-5-hepten-2-one, geranylacetone, $\beta$-ionone, and linalool as determined from spiking or GC-olfactometry (GC-O) studies (Baldwin et al., 2004; Tandon et al., 2000, 2001). There 
Table 6. $F$ values and significant levels from analysis of variants (ANOVA) on 29 volatiles of 29 tomato genotypes over 6 years, and one to three harvest seasons per year. ${ }^{\mathrm{z}}$

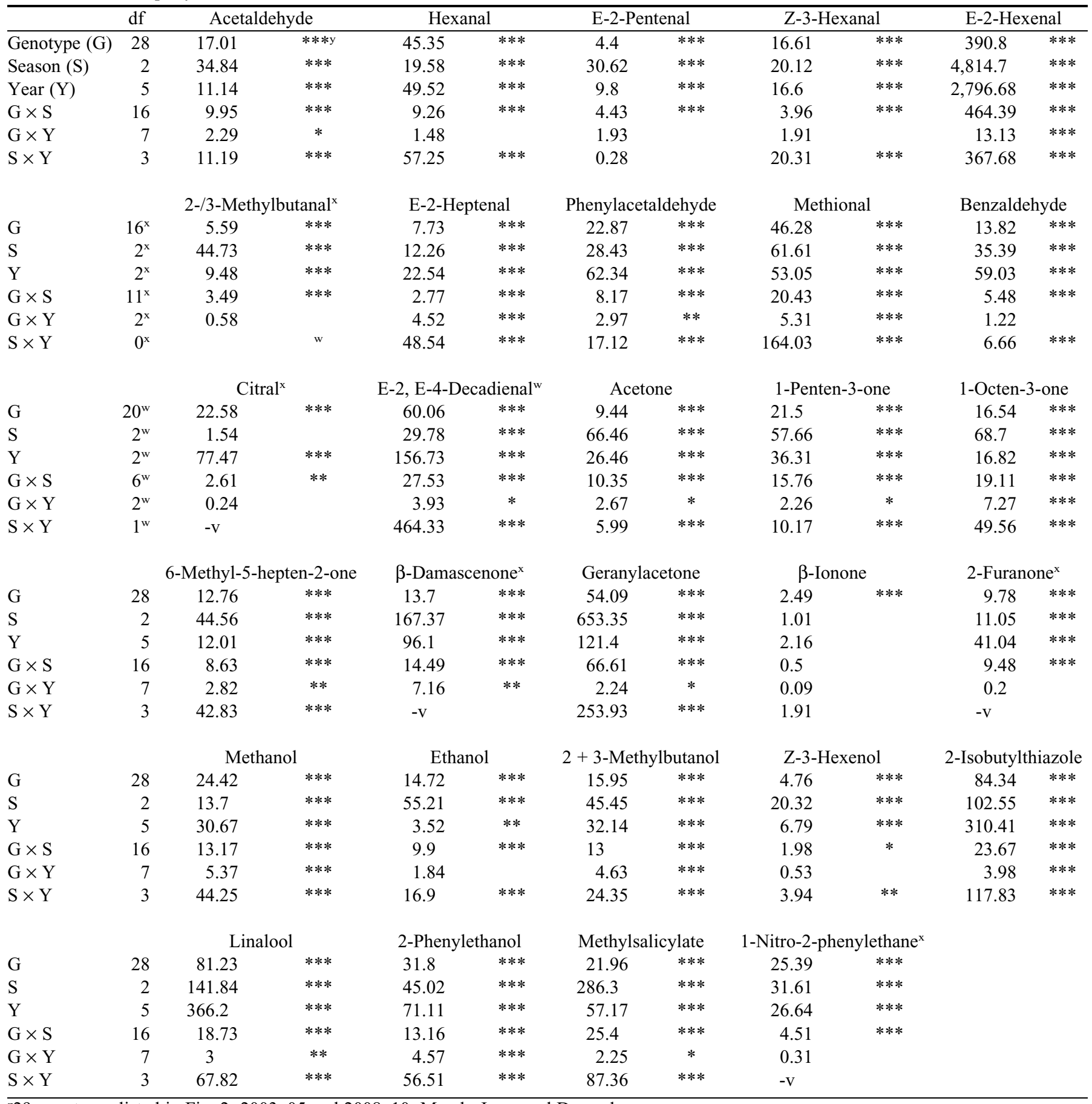

z29 genotypes listed in Fig. 2; 2003-05 and 2008-10; March, June, and December.

y*,** and $* * *$ indicates significance at $P \leq 0.05,0.01$, and 0.001 , respectively.

x2008-10 data only.

w2003-05 data only.

${ }^{\mathrm{N}}$ No interaction was calculable.

were 16 volatiles that showed no difference between these two genotypes (Table 7).

Comparing sensory and chemical data for the 29 genotypes over 6 years, with one to three seasons per year, showed correlations between chemical compounds and sensory perception of sweetness, sourness, and overall tomato flavor (Table 8). Many chemical compounds had significant and positive correla- tions with perception of sweetness $(P \geq 0.05)$ including sugar measurements, as expected (SS, TS, glucose, fructose, SE, SS/TA), and also many volatiles (acetaldehyde, hexanal, trans-2-hexenal, 1-penten-2-one, 6-methyl-5-hepten-2-one, geranylacetone, $\beta$-ionone, 2+3-methylbutanol, cis-3-hexenol, and methylsalicylate), although only SS, TS, glucose, fructose, and SE had coefficients ( $r$ values) greater than 0.4. Quite a few compounds 
Table 7. Concentration of volatiles emitted from 'Fla. 8153' and 'Florida 47' tomatoes tested over 6 years and one to three harvest seasons per year. $^{\mathrm{z}}$

\begin{tabular}{|c|c|c|c|c|c|c|c|}
\hline \multirow[b]{2}{*}{ Compound } & \multirow{2}{*}{$\begin{array}{l}\text { Chemical Abstracts } \\
\text { Service (CAS) no. }\end{array}$} & \multirow{2}{*}{\multicolumn{2}{|c|}{$\frac{\text { Fla. 8153 Florida } 47}{\left(\mu \mathrm{L} \cdot \mathrm{L}^{-1}\right)}$}} & \multirow[b]{2}{*}{$t$ test $^{\mathrm{y}}$} & \multicolumn{3}{|c|}{ Sensory descriptor } \\
\hline & & & & & In water & In ethanol/methanol & In tomato homogenate \\
\hline \multicolumn{8}{|l|}{ Higher in 'Fla. 8153' } \\
\hline Acetaldehyde & $75-07-0$ & 0.96 & 0.75 & $*$ & & & $\begin{array}{l}\text { Sweet tomato/musty/ } \\
\text { tropical/floral }^{t}\end{array}$ \\
\hline $2+3$-Methylbutanal ${ }^{\mathrm{x}}$ & $96-17-3 / 590-86-3$ & 0.53 & 0.15 & $* * *$ & Bug spray/alcohol $^{\text {s }}$ & Nutty/glue/alcohol $^{\mathrm{s}}$ & Stale/rotten ${ }^{v}$, nutty/stale \\
\hline Citral $^{\mathrm{x}}$ & $5392-40-5$ & 0.41 & 0.19 & $* * *$ & & & Citrusy/fruity ${ }^{\mathrm{u}}$ \\
\hline Methional & $3268-49-3$ & 0.81 & 0.40 & $* * *$ & & & Potato/pungent ${ }^{\mathrm{u}}$ \\
\hline $\begin{array}{l}\text { 6-Methyl-5- } \\
\text { hepten-2-one }\end{array}$ & $110-93-0$ & 0.15 & 0.04 & $* * *$ & Raw greens/nutty ${ }^{v}$ & Alcohol/paint ${ }^{\mathrm{v}}$ & $\begin{array}{l}\text { Sweet/floral }{ }^{\mathrm{v}}, \\
\text { sweet }_{\text {floral }}{ }^{\mathrm{t}}\end{array}$ \\
\hline Geranylacetone & $3796-70-1$ & 0.46 & 0.10 & $* * *$ & & & Sweet/citrus/estery ${ }^{t}$ \\
\hline$\beta$-Ionone & $14901-07-6$ & 0.27 & 0.10 & $* * *$ & & & Floral/sweet ${ }^{t}$ \\
\hline 2-/3-Methylbutanol & $137-32-6 / 123-51-3$ & 0.36 & 0.28 & $* *$ & $\begin{array}{l}\text { Earthy/watermelon } \\
\text { rind }^{\mathrm{v}}\end{array}$ & Alcoholv $^{\mathrm{v}}$ & $\begin{array}{l}\text { Sweet/fresh }{ }^{\mathrm{v}} \text {, pungent/ } \\
\text { earthy }^{\mathrm{u}}\end{array}$ \\
\hline Linalool & $78-70-6$ & 0.15 & 0.11 & $* *$ & & & Citrus/fruity/sweet taste ${ }^{t}$ \\
\hline \multicolumn{8}{|l|}{ Higher in 'Florida 47 ' } \\
\hline Z-3-Hexenal & $6789-80-6$ & 10.06 & 14.15 & $*$ & Grass/tomato-like & $\begin{array}{l}\text { Alcohol/ } \\
\text { tomato-like }\end{array}$ & $\begin{array}{l}\text { Tomato/citrus }{ }^{\mathrm{v}} \text {, viny/ } \\
\text { green/grass/tomato }^{\mathrm{t}}\end{array}$ \\
\hline E-2-Hexenal & $6728-26-3$ & 1.18 & 1.54 & $* *$ & Floral/grass/apple ${ }^{\mathrm{v}}$ & Fruity/almond/vine ${ }^{\mathrm{v}}$ & $\begin{array}{l}\text { Stale/green/vine }{ }^{\mathrm{v}} \text {, green/ } \\
\text { grass/vine/stale }\end{array}$ \\
\hline E-2-Heptenal & $18829-55-5$ & 0.06 & 0.11 & $* * *$ & & & Dried fruits ${ }^{\mathrm{u}}$ \\
\hline Z-3-Hexenol & $928-96-1$ & 0.08 & 0.13 & $* * *$ & Leafy/cut grass ${ }^{v}$ & Fresh cut grass ${ }^{\mathrm{v}}$ & $\begin{array}{l}\text { Green/celery }{ }^{\mathrm{v}} \text {, processed } \\
\text { tomato/green/celery }\end{array}$ \\
\hline \multicolumn{8}{|l|}{ Not significantly different } \\
\hline Phenylacetaldehyde & $122-78-1$ & 0.09 & 0.07 & & $\begin{array}{l}\text { Green, pungent, } \\
\text { honey-like }^{\text {s }}\end{array}$ & & \\
\hline E-2, E-4-Decadienal ${ }^{\mathrm{w}}$ & $25152-84-5$ & 0.69 & 0.60 & & & & Earthy/musty ${ }^{\mathrm{u}}$ \\
\hline Hexanal & $66-25-1$ & 1.51 & 1.95 & & Grassy/green ${ }^{v}$ & Rancid/stale oil ${ }^{\mathrm{v}}$ & $\begin{array}{l}\text { Stale/grassy/green }{ }^{v}, \\
\text { green/grass/mint }^{t}\end{array}$ \\
\hline E-2-Pentenal & $1576-87-0$ & 0.26 & 0.15 & & $\begin{array}{l}\text { Strawberry/fruit/ } \\
\text { tomato }^{\mathrm{r}}\end{array}$ & & \\
\hline Benzaldehyde & $100-52-7$ & 0.07 & 0.08 & & & & Peaches/fruity ${ }^{\mathrm{v}}$ \\
\hline Acetone & $67-64-1$ & 0.54 & 0.52 & & Glue/alcoholv ${ }^{v}$ & Sweet $^{v}$ & Green $^{\mathrm{w}}$, fruity $/$ green $^{\mathrm{u}}$ \\
\hline 1-Penten-3-one & $1629-58-9$ & 0.18 & 0.13 & & Glue/oil/pungent ${ }^{\mathrm{v}}$ & Pungent/rancid ${ }^{\mathrm{v}}$ & $\begin{array}{l}\text { Fresh/sweet }{ }^{\mathrm{v}}, \text { fresh/ } \\
\text { sweet/ fruity } \\
\text { taste/grassy }\end{array}$ \\
\hline$\beta$-Damascenone ${ }^{x}$ & $23696-85-7$ & 0.07 & 0.05 & & Apple. rose, honey ${ }^{r}$ & & \\
\hline 1-Octen-3-one & $4312-99-6$ & 0.05 & 0.05 & & & & Mushroom/earthy/soil ${ }^{v}$ \\
\hline 2-Furanone ${ }^{\mathrm{x}}$ & $497-23-4$ & 0.11 & 0.11 & & & & $\begin{array}{l}\text { Floral/sweet taste/fruity } \\
\text { taste }^{\mathrm{s}}\end{array}$ \\
\hline Methanol & $67-56-1$ & 166.39 & 141.23 & & Earthy/stale ${ }^{\mathrm{v}}$ & & \\
\hline Ethanol & $64-17-5$ & 6.66 & 5.71 & & Earthy/stale ${ }^{\mathrm{v}}$ & & Sweet taste $^{\mathrm{u}}$ \\
\hline 2-Phenylethanol & $60-12-8$ & 0.04 & 0.03 & & Floral/roses ${ }^{\mathrm{v}}$ & Fruity/green/leafy ${ }^{\mathrm{v}}$ & $\begin{array}{l}\text { Alcohol/nutty }{ }^{\mathrm{v}} \text {, } \\
\text { alcohol/nutty }{ }^{\mathrm{r}}\end{array}$ \\
\hline 2-Isobutylthiazol & $18640-74-9$ & 0.13 & 0.16 & & Fermented/plastic ${ }^{\mathrm{u}}$ & Acetone $/$ medicine ${ }^{u}$ & $\begin{array}{l}\text { Pungent } / \text { bitter }^{\mathrm{v}} \text {, } \\
\text { pungent } / \text { medicinal }^{\mathrm{r}}\end{array}$ \\
\hline $\begin{array}{l}\text { 1-Nitro-2- } \\
\text { phenylethane }^{\mathrm{x}}\end{array}$ & $6125-24-2$ & 0.06 & 0.07 & & Floral/spice ${ }^{\mathrm{r}}$ & & \\
\hline Methylsalicylate & $119-36-8$ & 0.10 & 0.09 & & Pepper mint ${ }^{\mathrm{r}}$ & & \\
\hline
\end{tabular}

z2003-05 and 2008-10; March, June, and December.

${ }^{y} t$ test, when next to data: $* * *$ and $* * *$ indicate significance at $P \leq 0.05,0.01$, and 0.001 , respectively.

${ }^{\mathrm{x}}$ Compounds detected in 2008-10 samples only.

${ }^{\mathrm{w}}$ Compounds detected in 2003-05 samples only.

vandon et al., 2000.

uTandon et al., 2001.

'Baldwin et al., 2008.

'University of Florida, 2015.

${ }^{\mathrm{r}}$ Acree and Heinrich, 2004. 
Table 8. Pearson correlation coefficient (linear relationship, Pearson's r) between sensory hedonic ratings and flavor chemical contents for 29 tomato genotypes tested in one to three seasons over 6 years. ${ }^{\mathrm{z}}$

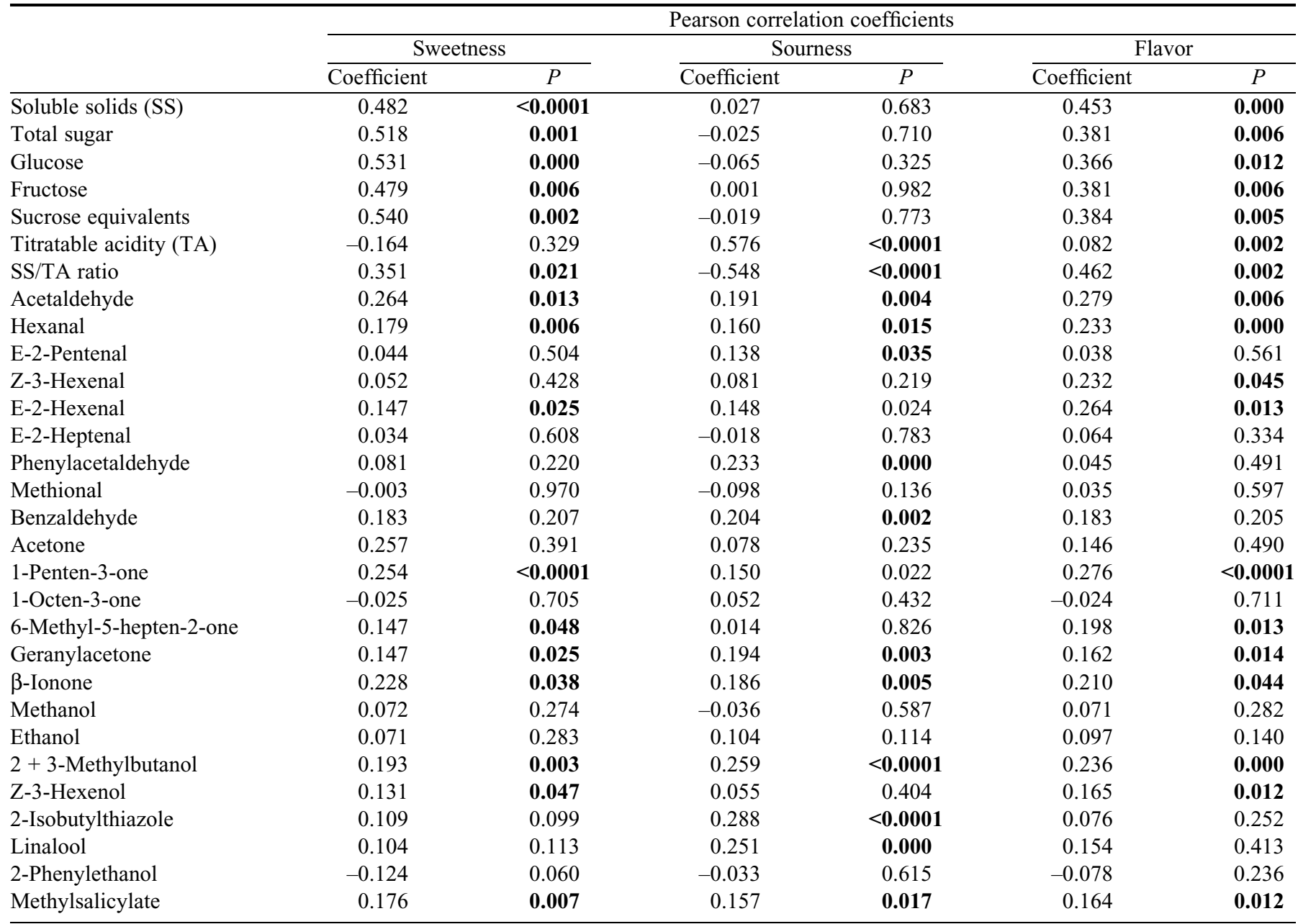

Bold numbers imply significance at $P<0.05$.

z29 genotypes listed in Fig. 2; 2003-05 and 2008-10; March, June, and December.

showed significant correlations to perception of sourness including acid measurements (positively to TA and negatively to SS/TA ratio) and volatiles (acetaldehyde, hexanal, trans-2pentenal, phenylacetaldehyde, benzaldehyde, genanylacetone, $\beta$-ionone, $2+3$-methylbutanol, 2-isobutylthiazole, linalool, and methylsalicylate), with only TA and SS/TA showing an absolute value above 0.4 . For linear relationships (all positive) to perception of overall tomato flavor, all the soluble compound measurements were significantly correlated (SS, TS, glucose, fructose, SE, TA, and SS/TA ratio) as well as many volatiles (acetaldehyde, hexanal, cis-3-hexenal, trans-2-hexenal, 1-penten-3-one, 6-methyl-5hepten-2-one, geranylacetone, $\beta$-ionone, $2+3$-methylbutanol, cis-3-hexenol, and methylsalicylate) with only SS and SS/TA ratio having $r$ values greater than 0.4 .

Multiple regression was then used to determine the contribution of aroma volatiles for enhancement or suppression of perception of sweetness, sourness, or overall tomato flavor in a 2-predictor model (Table 9). For perception of sweetness, SE was chosen as the companion variable for prediction of the perception of sweetness, since it encompasses both sugars weighted for sweetness and was highly correlated to sweetness (Table 8). Perception of sweetness was significantly $(P=0.002)$ enhanced by SE (Table 8) along with the volatiles hexanal, trans- 2-hexenal, 1-penten-3-one, geranylacetone, $2+3$-methylbutanol, cis-3-hexenol, 2-phenylethanol, and methylsalicylate at $P<$ 0.05 , in some agreement with Bartoshuk et al. (2013), while 2-phenylethanol suppressed perception of sweetness $(P \leq 0.05)$. The sourness model included TA, since it measures general acids (titratable acids) and was highly correlated $(P=0.0001)$ with sourness (Table 8), which along with trans-2-hexenal, geranylacetone, $2+3$-methylbutanol, 2-isobutylthiazole, and methylsalicylate enhanced sourness perception, while methional and 6-methyl-5-hepten-2-one significantly $(P<0.05)$ suppressed perception of sourness. For overall tomato flavor, SS/TA was the chemical variable used, since it encompasses both sugars and acids and was highly correlated $(P=0.002)$ with flavor (Table 8 ), and along with acetaldehyde, hexanal, cis-3-hexenal, trans-2-hexenal, 1-penten-3-one, geranylacetone, ethanol, $2+3$-methylbutanol, cis3-hexenol, and methyl salicylate, enhanced perception of overall tomato flavor at $P \leq 0.05$. If $P \leq 0.1$ were to be used for significance, as is acceptable for sensory data (Meilgaard et al., 1991), then benzaldehyde, 6-methyl-5-hepten-2-one, and 2-isobutylthiazole also enhanced flavor perception. It is interesting that most of the volatiles that enhanced sweetness or sourness also enhanced overall flavor. Also interesting was that several of the volatiles that enhanced sweetness (with SE) 
Table 9. Multiple regression analysis for volatiles to determine the contribution of a volatile to enhance/suppress hedonic sensory ratings of overall flavor, sweetness, and sourness based on a two-predictor model. Samples were from 29 tomato genotypes tested in one to three seasons per year over 6 years. ${ }^{z}$

\begin{tabular}{|c|c|c|c|c|c|c|}
\hline \multirow{3}{*}{$\frac{\text { Dependent variable }^{\mathrm{y}}}{\text { Basic independent variable }}$} & \multicolumn{2}{|c|}{ Sweetness } & \multicolumn{2}{|c|}{ Sourness } & \multicolumn{2}{|c|}{ Flavor } \\
\hline & \multicolumn{2}{|c|}{ Sucrose equivalents } & \multicolumn{2}{|c|}{ TA } & \multicolumn{2}{|c|}{ SS/TA ratio ${ }^{x}$} \\
\hline & $\mathrm{t}$ & $P$ & $\mathrm{t}$ & $P$ & $\mathrm{t}$ & $P$ \\
\hline Acetaldehyde & 1.6100 & 0.1084 & 0.4100 & 0.6807 & 2.8300 & $\overline{0.0050}$ \\
\hline E-2-Pentenal & 0.3500 & 0.7266 & 1.0200 & 0.3067 & 0.9400 & 0.3479 \\
\hline Z-3-Hexenal & 0.5900 & 0.5541 & -1.3200 & 0.1866 & 2.3600 & 0.0191 \\
\hline E-2-Hexenal & 2.3400 & 0.0199 & 2.7800 & 0.0059 & 2.7600 & 0.0062 \\
\hline Phenylacetaldehyde & 0.6200 & 0.5331 & 1.0200 & 0.3075 & 0.7100 & 0.4810 \\
\hline Methional & -0.4800 & 0.6308 & -2.0500 & 0.0409 & 1.1200 & 0.2625 \\
\hline Benzaldehyde & 0.6100 & 0.5395 & 0.7500 & 0.4560 & 1.7300 & 0.0855 \\
\hline Acetone & 0.3200 & 0.7482 & -1.3500 & 0.1768 & 1.4000 & 0.1614 \\
\hline 1-Penten-3-one & 3.4200 & 0.0007 & 1.3000 & 0.1948 & 4.4200 & $<0.0001$ \\
\hline 1-Octen-3-one & -0.7500 & 0.4534 & 0.5100 & 0.6096 & 0.2800 & 0.7820 \\
\hline Ethanol & -0.0400 & 0.9690 & -0.4900 & 0.6212 & 2.0100 & 0.0451 \\
\hline 2 + 3-Methylbutanol & 2.7500 & 0.0064 & 2.2000 & 0.0285 & 3.8900 & 0.0001 \\
\hline Z-3-Hexenol & 2.2400 & 0.0257 & -0.3300 & 0.7422 & 2.4600 & 0.0147 \\
\hline 2-Isobutylthiazole & 1.7600 & 0.0797 & 2.3200 & 0.0212 & 1.7700 & 0.0774 \\
\hline Linalool & 1.7400 & 0.0826 & 1.9500 & 0.0526 & 1.5100 & 0.1311 \\
\hline 2-Phenylethanol & -2.3300 & 0.0208 & 0.9300 & 0.3554 & 0.5500 & 0.5849 \\
\hline Methylsalicylate & 3.8600 & 0.0001 & 3.1000 & 0.0021 & 2.7300 & 0.0067 \\
\hline
\end{tabular}

TA = titratable acidity.

Bold numbers imply significance at $P<0.05$.

z29 genotypes listed in Fig. 2; 2003-05 and 2008-10; March, June, and December; $\mathrm{t}=$ parameter estimate/SE.

${ }^{y}$ Sensory rating (1-9 scale).

${ }^{\times}$Soluble solids/titratable acidity ratio.

also enhanced sourness (with TA) including trans-2-hexenal, geranylacetone, $2+3$-methylbutanol, and methylsalicylate. Stevens et al. (1977) found that sweetness and sourness were related and concluded that a higher level of acidity was necessary for tomatoes to have consistent sweetness. Perhaps these volatiles enhanced acidity and thus indirectly enhanced sweetness. Table 7 shows descriptors for the various volatile compounds analyzed in this study, showing how their descriptors change depending on the matrix (water, alcohol, or deodorized tomato homogenate). Some of the volatiles that enhanced perception of sweetness are sweet or fruity in a tomato matrix (acetaldehyde, $2+3$-methylbutanol, geranylacetone, and 1-penten-3-one). On the other hand, methylsalicylate has been described as wintergreen mint, and the C-6 aldehydes and alcohol are all described as green (hexanal, trans-2-hexenal, cis-3-hexenal, and cis-3-hexenol). The aroma volatiles that enhanced sourness included the sulfur volatile unique to tomato, 2-isobutylthiazole, and a C-6 aldehyde and alcohol (cis-3-hexenal and cis-3hexenol, respectively) as well as methylsalicylate, which give green/mint notes along with the somewhat sweet/earthy $2+$ 3-methylbutanol. The potato/earthy methional and sweet/floral 6-methy-5-hepten-2-one (in tomato matrix) appear to have detracted from sour perception.

To compare all the sensory and chemical data, PCA analysis was used, which explained $71.18 \%$ of the sensory and chemical data variation in two principal components (F1 and F2), and revealed that there were genotype and seasonal effects (Fig. 2). Dividing the figure into quadrants, quadrant A had relatively high loadings for component F2 and low loadings for F1, quadrant $\mathrm{B}$ had high loadings for components $\mathrm{F} 1$ and F2, quadrant $\mathrm{C}$ had low loadings for $\mathrm{F} 1$ and 2, while quadrant $\mathrm{D}$ had low loadings for component F2 and high for F1. Quadrants A and $\mathrm{C}$ were devoid of flavor descriptors and flavor chemical components including all volatiles due to low loading on F1. All of the 'Fla. 8153' samples and related genotypes through its parents (Fla. 7907 and Fla. 8059) were in B and D quadrants, associated with high loadings for sourness, sweetness, and flavor perception as well as all volatiles, (total) sugars (TS = total sugars: fructose, glucose), and moderate for SE and acid (TA), with higher $\mathrm{pH}$ in opposite quadrant measurements. Contrarily, almost all of the 'Florida 47', and several other low-scoring genotypes ('Ugly Ripe', Cluster, 'Sanibel', 'Solar Fire') were in quadrants $\mathrm{A}$ and $\mathrm{C}$ which had low loadings for most chemical and sensory measurements including sourness, sweetness, flavor, volatiles, sugars, or acids. Other than a few outliers ('Florida 47' June 2008 and 2009 and 'Sanibel' June 2010 , which were just over into quadrant D), most of the March- and June-harvested samples were in quadrants C and D (mostly D) with high loadings on component F1 for flavor and sweetness perception as well as some volatiles and all sugar measurements (SS, glucose, fructose, SS/TA, sucrose equivalents, total sugars). December-harvested fruit (highlighted in 


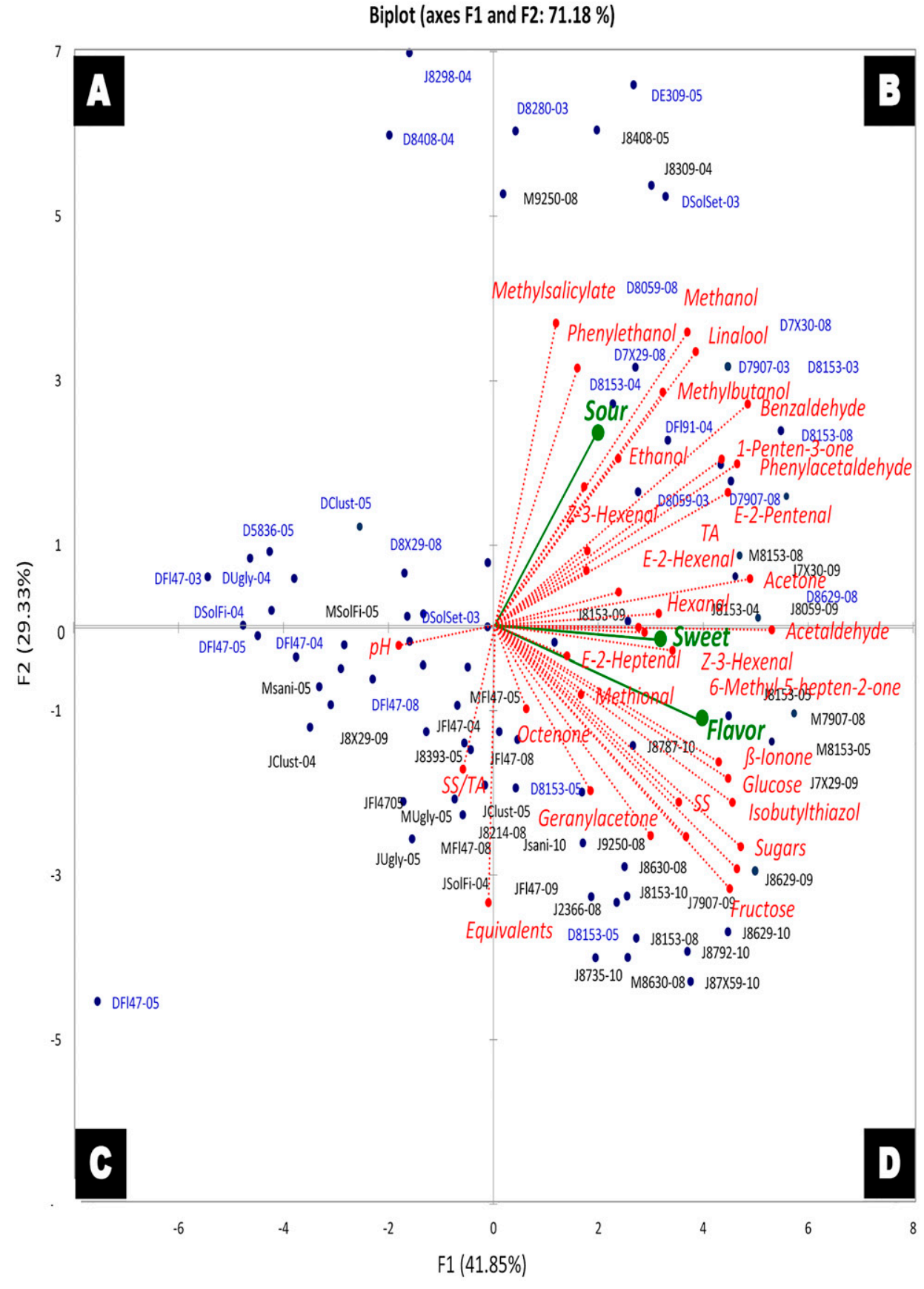

Fig. 2. Principal component analysis biplot based on sensory and chemical data of 29 tomato genotypes over 6 years with one to three harvests per year.

blue) were mostly found in quadrant $\mathrm{B}$, followed by $\mathrm{A}$, with a few in $\mathrm{C}$ and $\mathrm{D}$, with $\mathrm{B}$ having high loadings for some volatiles, sourness perception, and acid measurements (TA), opposite of higher $\mathrm{pH}$ (in the opposite quadrant) on components F1 and F2, and quadrant A being devoid of any sensory descriptors or chemical components.

Cluster analysis was calculated based on all chemical and sensory data for the genotypes (Fig. 1). High flavor-scoring genotypes (Table 3), including 'Fla. 8153', parent Fla. 7907, and related genotypes clustered together along with 'Fla. 8153 's other parent (Fla. 8059, midrange in flavor scores), while low flavor scoring genotypes, such as 'Florida 91' and
'Florida 47', were significantly separated from 'Fla. 8153' and related genotypes by cluster analysis. The group that had the largest distance units (4.1748) from the group that included 'Fla. 8153' included 9250, Cluster tomatoes, 'Sanibel', 8393, 8787, 'Solar Fire', 'Ugly Ripe', and 'Florida 47' (Fig. 2), which except for 9250 and 8393, generally had low flavor scores (Table 3).

When comparing only 'Florida 47' and 'Fla. 8153' using PCA (Fig. 3), $85.98 \%$ of the variation for all chemical and sensory data was explained in two PC components (F1 and F2). Quadrants B and D contained almost all the volatiles, most of the 'Fla. 8153' and June samples, and were associated with flavor and sweetness perception as well as (total) sugars and other sugar measurements (sugars = TS, glucose, fructose and SE). Quadrants $A$ and $C$ had most of the 'Florida 47' and December (highlighted in blue) samples (March samples being interspersed between December and June), and were associated with sourness perception and TA, as well as a lack of aroma volatiles. The few 'Fla. 8153' samples found in Quadrants $\mathrm{A}$ and $\mathrm{C}$ were all from December harvests.

The findings of the study show that there is much yearly and seasonal variation for tomato flavor quality as seen by variation in sensory perception (Tables 2 and 3; Fig. 2) backed up by variation in levels of various chemical flavor components (Tables 4 and 6; Fig. 2). This is evident for all the genotypes investigated generally, and for the two cultivars with the most data, 'Fla. 8153' and 'Florida 47' (Tables 3, 5, and 7; Fig. 3). From these data, insight into seasonal effects and chemical drivers of tomato flavor can be gained.

The trials represent a diversity of growing environments. In general, spring crops (June harvest) go from shorter to longer days with increasing temperatures and solar radiation; fall crops (December harvest) go from longer to shorter days with decreasing temperatures and solar radiation; and winter production would tend to be under short days with relatively lower temperatures and solar radiation. Seasonal differences were evident, despite the yearly and seasonal variations, in that flavor chemical components and flavor perception (overall flavor and sweetness) were more associated with June followed by March and least associated with December harvest seasons (Figs. 2 and 3). This was confirmed by the fact that June harvests were more associated with sugars, 


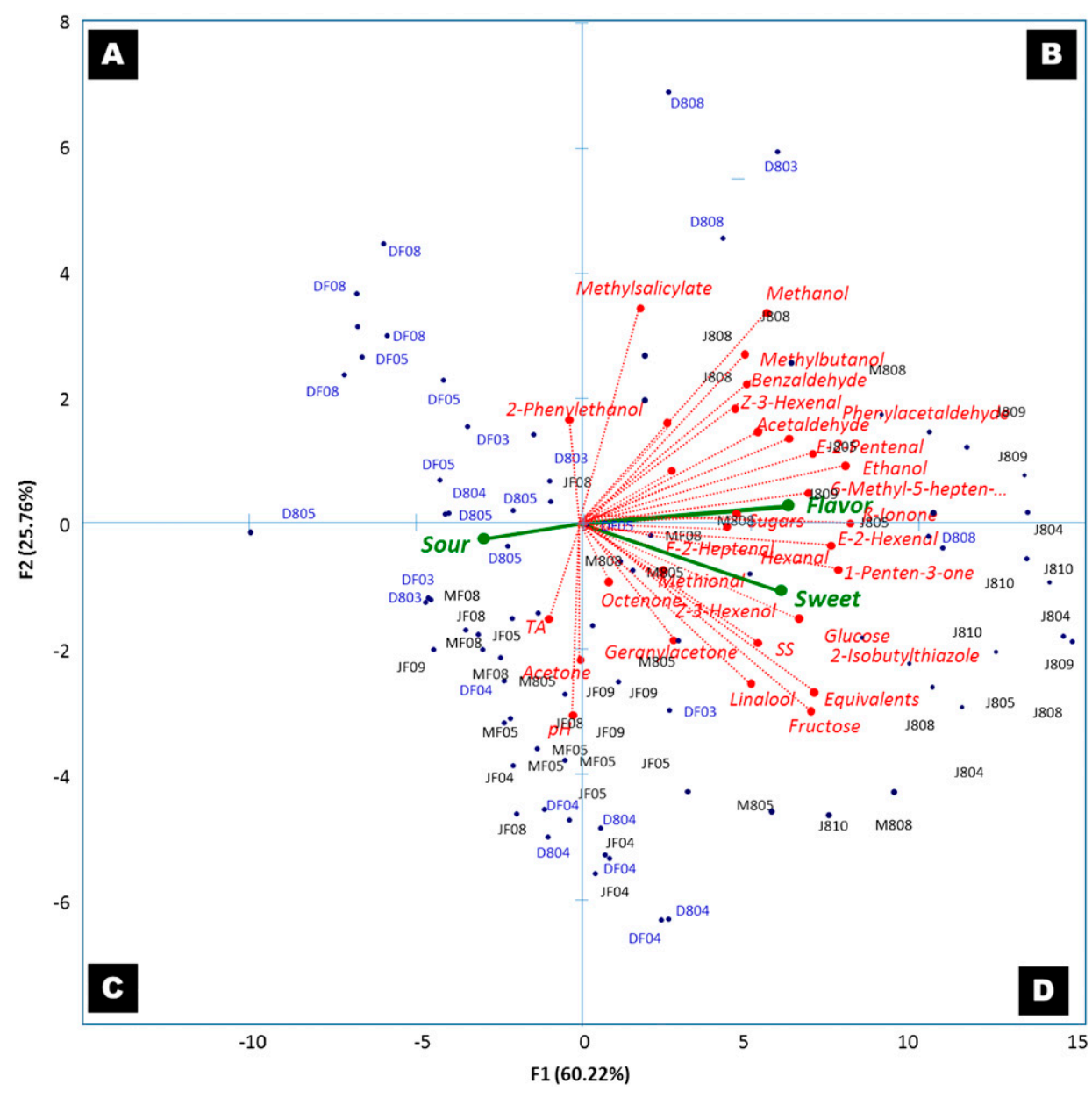

Fig. 3. Principal component analysis biplot based on sensory and chemical data of 'Florida 47' and 'Fla. 8153' tomatoes over 6 years and 10 harvests.

followed by March and lastly December (Figs. 2 and 3). The precise cause of increased sugars in June is not known although solar radiation, daylength, and temperatures were all higher at that time of year (Table 10). This likely relates to increased photosynthesis resulting from increased solar radiation over long days. Georgelis et al. (2006) showed significant line $\times$ season (fall, spring) interaction in Florida for inheritance of sugars, with sugar levels being generally higher in spring for genotypes with genetically increased sugars, and suggested that this was due to higher solar radiation in spring than in fall. Early reports also showed that higher solar radiation was associated with higher sugars (Davies and Hobson, 1981; Winsor and Adams 1976). Our results do support the earlier findings, but possible effects of temperature and perhaps daylength could also play a role.
Despite the yearly and seasonal variation, drivers of tomato flavor were distinguishable and not surprisingly included sugars, acids, and aroma volatiles in general. In particular, the volatile aldehydes (especially green-note C-6 aldehydes and a related alcohol, cis-3hexenol); fruity ketones and unique volatiles like the sulfur compound, 2-isobutylthiazole; the sweet-note alcohol, 2 + 3-methylbutanol; and the citrusy terpene alcohol, linalool and the terpinoid aldehyde, citral (which comprises the cis-/translemony isomers of geranial and neral) seemed to play important roles. Tieman et al. (2012) had similar findings relating aroma volatiles to consumer preferences. Differences between the more flavorful 'Fla. 8153' and 'Florida 47' were also evident over the noise of seasons and years. The lower flavor ratings for 'Florida 47' compared with 'Fla. 8153' may have been caused by lower sugars and higher acids, but also aroma volatiles with the former having a lower sugar/acid ratio, more green notes (C-5 and C-6 aldehydes and related alcohol), and fewer fruity/floral notes (Table 7), mostly ketones (6-methyl-5-hepten-2-one, geranylacetone, $\beta$-ionone); other aldehydes (acetaldehyde); and alcohol $(2+3$-methylbutanol) and terpenes (citral and linalool). However, 'Fla. 8153' also had higher sweetness ratings and sugar levels, which are highly correlated to overall flavor (Table 8) (Malundo et al., 1995). It is therefore difficult to determine the effect of the aroma volatiles alone. A strong point within this dataset suggests that the volatiles as measured over so many seasons and locations, delivering significant differences, rising above the environmental noise, probably relate to the flavor differences in the two cultivars. Thus, the data provide volatiles and volatile levels for tomato breeders to target in their flavor improvement work. Further work is needed to verify the importance of this suite of volatiles, which will not be a trivial task; however, these data offer a manageable number of volatiles on which to focus. In addition, more was learned in this study about flavor perception. Many of these same volatiles were positively correlated with perception of

Table 10. Summary of weather data over the 2 weeks before harvest for the three tomato growing environments used in this study.

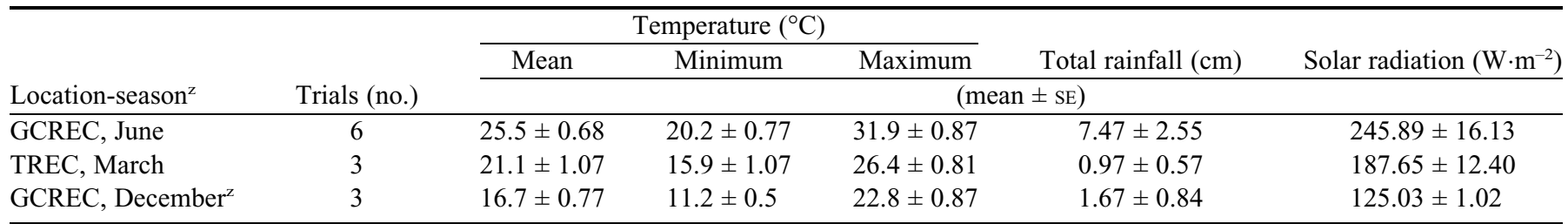

${ }^{\mathrm{z}}$ GCREC $=$ Gulf Coast Research \& Education Center, Wimauma, FL; TREC $=$ Tropical Research \& Education Center, Homestead, FL.

y2003 data not available. 
sweetness (acetaldehyde, 1-penten-3-one, 6-methyl-5-hepten-2one, geranylyacetone, $\beta$-ionone) or enhanced sweetness in combination with sugars (1-penten-3-one, geranylacetone), or enhanced overall flavor in combination with the sweet/sour SS/ TA ratio (acetaldehyde, hexanal, cis-3-hexenal, trans-2-hexenal, benzaldehyde, 1-penten-3-one, 6-methyl-5-hepten-2-one, geranylacetone, ethanol, $2+3$-methylbutanol, cis-3-hexenol, 2-isobutylthiazole, and methylsalicylate) (Table 9). In summary, it appears that tomato flavor quality is based on a balanced volatile profile (less green and more fruity volatiles) with moderate acid levels and relatively high levels of sugars.

\section{Literature Cited}

Acree, T. and A. Heinrich. 2004. Flavornet and Human Odor Space. 16 July 2015. <http://www.flavornet.org/flavornet.html $>$.

Bai, J., E.A. Baldwin, Y. Imahori, I. Kostenyuk, J. Burns, and J.K. Brecht. 2011. Chilling and heating may regulate C6 volatile aroma production by different mechanisms in tomato (Solanum lycopersicum) fruit. Postharvest Biol. Technol. 60:111-120.

Baldwin, E.A., M.O. Nisperos-Carriedo, R.A. Baker, and J. Scott. 1991. Quantitative analysis of flavor parameters in six Florida tomato cultivars (Lycopersicon esculentum Mill). J. Agr. Food Chem. 39:1135-1140.

Baldwin, E.A., J.W. Scott, M.A. Einstein, T.M.M. Malundo, B.T. Carr, R.L. Shewfelt, and K.S. Tandon. 1998. Relationship between sensory and instrumental analysis for tomato flavor. J. Amer. Soc. Hort. Sci. 123:906-915.

Baldwin, E.A., K. Goodner, A. Plotto, K. Pritchett, and M. Einstein. 2004. Effect of volatiles and their concentration on perception of tomato descriptors. J. Food Sci. 69:S310-S318.

Baldwin, E.A., A. Plotto, and K. Goodner. 2007. Shelf-life versus flavour-life for fruits and vegetables: How to evaluate this complex trait. Stewart Postharvest Rev. 1:2-10.

Baldwin, E.A., K. Goodner, and A. Plotto. 2008. Interaction of volatiles, sugars and acids on perception of tomato aroma and flavor descriptors. J. Food Sci. 73:S294-S307.

Baldwin, E., A. Plotto, J. Manthey, G. McCollum, J. Bai, M. Irey, R. Cameron, and G. Luzio. 2010. Effect of Liberibacter infection (Huanglongbing disease) of citrus on orange fruit physiology and fruit/ fruit juice quality: Chemical and physical analyses. J. Agr. Food Chem. 58:1247-1262.

Baldwin, E.A., A. Plotto, J. Narciso, and J. Bai. 2011. Effect of 1-methylcycloprene on tomato flavor components, shelf life and decay as influenced by harvest maturity and storage temperature. J. Sci. Food Agr. 91:969-980.

Bartoshuk, L.M. and H.J. Klee. 2013. Better fruits and vegetables through sensory analysis. Curr. Biol. 23:R374-R378.

Bartoshuk, L., T.A. Colquhoun, D.G. Clark, M. Schwieterman, C.A. Sims, V. Whitaker, H.J. Klee, D. Tieman, and L. McIntyre. 2013. Compositions and methods for modifying perception of sweet taste. U.S. Patent application US20130280400 A1 (Application No. US 13/ 869,132). U.S. Patent Trademark Office, Washington, DC.

Bruhn, C.M., N. Feldman, J.H. Garlitz, E. Ivans, M. Marshall, A. Riley, D. Thurber, and E. Williamson. 1991. Consumer perception of quality: Apricots, cantaloupes, peaches, pears, strawberries, and tomatoes. J. Food Qual. 14:187-195.

Buttery, R.G. 1993. Quantitative and sensory aspects of flavor of tomato and other vegetables and fruits, p. 259-286. In: T.E. Acree and R. Teranishi (eds.). Flavor science: Sensible principles and techniques. Amer. Chem. Soc., Washington, DC.

Buttery, R.G., R. Teranishi, and L.C. Ling. 1987. Fresh tomato aroma volatiles: A quantitative study. J. Agr. Food Chem. 35:540-544.

Buttery, R.G., R. Teranishi, R.A. Flath, and L.C. Ling. 1989. Fresh tomato volatiles: Composition and sensory studies, p. 213-222. In: R. Teranishi, R.G. Buttery, and T. Shahidi (eds.). Flavor chemistry. Amer. Chem. Soc., Washington, DC.
Carli, P., A. Barone, V. Fogliano, L. Frusciante, and M.R. Ercolano. 2011. Dissection of genetic and environmental factors involved in tomato organoleptic quality. BMC Plant Biol. 11:58.

Davies, J.N. and G.E. Hobson. 1981. The constituents of tomato fruitthe influence of environment, nutrition, and genotype. CRC Crit. Rev. Food Sci. Nutr. 15:205-280.

Georgelis, N., J.W. Scott, and E.A. Baldwin. 2006. Inheritance of high sugars from tomato accession PI 270248 and environmental variation between seasons. J. Amer. Soc. Hort. Sci. 131:41-45.

Jiménez-Gómez, J.M. and J.N. Maloof. 2009. Sequence diversity in three tomato species: SNPs, markers, and molecular evolution. BMC Plant Biol. 9(85):1-11.

Klee, H.J. 2010. Tanksley review: Improving the flavor of fresh fruits: Genomics, biochemistry, and biotechnology. New Physiol. 187:44-56.

Klee, H.J. and D.M. Tieman. 2013. Genetic challenges of flavor improvement in tomato. Trends Genet. 29:257-262.

Koehler, P.E. and S.J. Kays. 1991. Sweet potato flavor: Quantitative and qualitative assessment of optimum sweetness. J. Food Qual. 14:241-249.

Malundo, T.M.M., R.L. Shewfelt, and J.W. Scott. 1995. Flavor quality of fresh tomato (Lycopersicon esculentum Mill.) as affected by sugar and acid levels. Postharvest Biol. Technol. 6:103-110.

Maul, F., S.A. Sargent, M.O. Balaban, E.A. Baldwin, D.J. Huber, and C.A. Sims. 1998. Aroma volatile profiles from ripe tomato fruit are influenced by physiological maturity at harvest: An application of electronic nose technology. J. Amer. Soc. Hort. Sci. 123:10941101.

Maul, F., S.A. Sargent, C.A. Sims, E.A. Baldwin, M.O. Balaban, and D.J. Huber. 2000. Storage temperatures affect tomato flavor and aroma quality. J. Food Sci. 65:1228-1237.

Meilgaard, M., G.V. Civille, and B.T. Carr. 1991. Sensory evaluation techniques. 2nd ed. CRC Press, Boca Raton, FL.

Mikkelsen, R.L. 2005. Tomato flavor and plant nutrition: A brief review. Better Crops 89(2):14-15.

Olson, S.M., W.M. Stall, G.E. Vallad, S.E. Webb, S.A. Smith, E.H. Simonne, E.J. McAvoy, and B.M. Santos. 2010. Tomato production in Florida, p. 295-316. In: S.M. Olson and B. M.Santos (eds.). Vegetable production handbook for Florida 2010-2011. Inst. Food Agr. Sci., Univ., Gainesville, FL.

Scott, J.W. 2002. A breeder's perspective on the use of molecular techniques for improving fruit quality. HortScience 37:464-467.

Scott, J.W., E.A. Baldwin, H.J. Klee, J.K. Brecht, S.M. Olson, J.A. Bartz, and C.A. Sims. 2008. Fla. 8153 Hybrid Tomato; Fla. 8059 and Fla. 7907 breeding lines. HortScience 43:2228-2230.

Song, J., B.D. Gardner, J.F. Holland, and R.M. Beaudry. 1997. Rapid analysis of volatile flavor compounds in apple fruit using SPME and GC/Time-of-flight mass spectrometry. J. Agr. Food Chem. 45:18011807.

Stone, H. and J.L. Sidel. 1997. Sensory evaluation practices. 2nd ed. Academic Press, New York, NY.

Stevens, M.A., A.A. Kadar, M. Albright-Holton, and M. Algazi. 1977. Genotypic variation for flavor and composition in fresh market tomatoes. J. Amer. Soc. Hort. Sci. 102:680-689.

Tandon, K.S., E.A. Baldwin, and R.L. Shewfelt. 2000. Aroma perception of individual volatile compounds in fresh tomatoes (Lycopersicon esculentum Mill.) as affected by the medium of evaluation. Postharvest Biol. Technol. 20:261-268.

Tandon, K.S., E.A. Baldwin, J.W. Scott, and R.L. Shewfelt. 2003. Linking sensory descriptors to volatile and nonvolatile components of fresh tomato flavor. J. Food Sci. 68:2366-2371.

Tandon, K.S., M. Jordan, K.L. Goodner, and E.A. Baldwin. 2001. Characterization of fresh tomato aroma volatiles using GColfactometry. Proc. Florida State Hort. Soc. 114:142-144.

Thompson, A.E., M.L. Tomes, E.V. Wann, J.P. McCollum, and A.K. Stoner. 1965. Characteristics of crimson tomato fruit color. Proc. Amer. Soc. Hort. Sci. 86:610-616. 
Tieman, D.P., L.M. Bliss, L.M. McIntyre, A. Blandon-Ubeda, D. Bies, A.Z. Odabasi, G.R. Rodriguez, E. van der Knaap, M.G. Taylor, C. Goulet, M.H. Mageroy, D.J. Snyder, T. Colquhoun, H. Moskowitz, D.G. Clark, C. Sims, L. Bartoshuk, and H.J. Klee. 2012. The chemical interactions underlying tomato flavor preferences. Curr. Biol. $22: 1-5$.

University of Florida. 2015. Aroma Descriptors, CAS Number, Retention Indices and Thresholds of Volatile Compounds. 16 July 2015. $<$ http://www.crec.ifas.ufl.edu/crec_websites/Rouseff/website2002/ subpages/database_a_frameset.shtml $>$.
USDA Agricultural Marketing Service, United Fruit and Vegetable Association, Fruit and Vegetable Division. 2015. 22 July 2015. $<$ http://www.just.edu.jo/ jamali/tomatocolor.htm $>$.

Wang, L., E.A. Baldwin, A. Plotto, Z. Yu, and J. Bai. 2015. Effect of methyl salicylate and methyl jasmonate pre-treatment on the volatile profile in tomato fruit subjected to chilling temperature. Postharvest Biol. Technol. 108:28-38.

Winsor, G.W. and P. Adams. 1976. Changes in the composition and quality of tomato fruit throughout the season. Annu. Rpt., p. 134 142. Glasshouse Crops Res. Inst., Littlehampton, UK. 